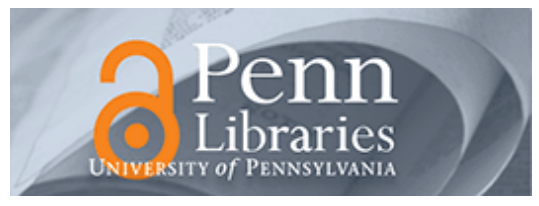

University of Pennsylvania

ScholarlyCommons

Finance Papers

Wharton Faculty Research

$1-2012$

\title{
Crime and property values: Evidence from the 1990s crime drop
}

Devin G. Pope

Jaren C. Pope

Follow this and additional works at: https://repository.upenn.edu/fnce_papers

Part of the Finance and Financial Management Commons

\section{Recommended Citation}

Pope, D. G., \& Pope, J. C. (2012). Crime and property values: Evidence from the 1990 s crime drop.

Regional Science and Urban Economics, 42 (1-2), 177-188. http://dx.doi.org/10.1016/

j.regsciurbeco.2011.08.008

This paper is posted at ScholarlyCommons. https://repository.upenn.edu/fnce_papers/96

For more information, please contact repository@pobox.upenn.edu. 


\title{
Crime and property values: Evidence from the 1990s crime drop
}

\begin{abstract}
Does a dramatic drop in crime lead to an increase in property values? To date, the literature on how crime influences property values has focused solely within a single metropolitan area and has been limited primarily to cross-sectional analysis. In this study we exploit the dramatic, nationwide decrease in crime that occurred in the 1990s to examine the relationship between changes in crime rates and property values. To do this, we compile information on changes in property values and crime during the 1990s in nearly 3000 urban zip codes throughout the U.S. Using a fixed-effects framework as well as an instrumental variables strategy, our analysis implies a large and statistically significant association between crime and property values. The estimated elasticities of property values with respect to crime range from -0.15 to -0.35 . Furthermore, zip codes in the top decile in terms of crime reduction saw property value increases of $7-19 \%$ during the 1990 s. Both the empirical analysis and a graphical analysis are suggestive that decreasing crime leads to increasing property values.
\end{abstract}

\section{Highlights}

- We exploit the sharp decrease in crime in the 1990s to examine the relationship between crime and property values. Information on changes in property values and crime in nearly 3000 U.S. zip codes are used to conduct the analysis. - Our analysis implies a large and statistically significant association between crime and property values. The top decile of zip codes (in terms of crime reduction) saw property value increases between 7 and 19\% during the 1990s.

\section{Keywords}

crime, property, values

Disciplines

Business | Finance and Financial Management 


\title{
Crime and Property Values: Evidence from the 1990's Crime Drop ${ }^{\dagger}$
}

\author{
Devin G. Pope \\ The Wharton School \\ University of Pennsylvania
}

\author{
Jaren C. Pope \\ Department of Ag. \& Applied Economics \\ Virginia Tech
}

This Draft: February 2009

(Do NOT distribute or cite without permission from the authors)

\begin{abstract}
Does a dramatic drop in crime lead to an increase in property values? To date, the literature on how crime influences property values has focused only within a single metropolitan area and has been limited primarily to cross-sectional analysis. In this study we exploit the dramatic, nationwide decrease in crime that occurred in the 1990s to examine the relationship between changes in crime rates and property values. To do this, we compile information on changes in property values and crime during the 1990s in nearly 3,000 urban zip codes throughout the U.S. Using a fixed-effects framework as well as an instrumental variables strategy, our analysis implies a large and statistically significant association between crime and property values. The estimated elasticities of property values with respect to crime range from -0.15 to -0.35 . Furthermore, zip codes in the top decile in terms of crime reduction saw property value increases of $7-19 \%$ during the 1990s. Both the empirical analysis and a graphical analysis suggest that causality runs from decreasing crime to increasing property values. These results imply that the crime drop was a major contributor to the recent resurgence of cities.
\end{abstract}

Keywords: Crime; Property Values

\footnotetext{
$\dagger$ We thank Philip Cook, Fernando Ferreira, Michael Greenstone, Nick Kuminoff, Lars Lefgren, Jonah Rockoff, and Todd Sinai for helpful discussions about this paper. The standard disclaimer applies.

* Corresponding Author. Assistant Professor, Department of Agricultural and Applied Economics (0401), Virginia Tech, Blacksburg, VA 24061. Email: jcpope@vt.edu; Phone: (540) 231-4730; Fax: (540) 2317417.
} 


\section{Introduction}

Crime has traditionally been one of the great challenges facing urban areas in the United States. The direct and indirect costs of crime are tremendous. Anderson (1999) estimates that the net annual burden of crime exceeds one trillion dollars in the U.S. Direct costs include destruction of life, destruction of property, expenditures on criminal justice programs, and expenditures on private security. Indirect costs of crime include the opportunity costs of victims, criminals and prisoners, but also the fear and anxiety that salient criminal acts such as murders, vandalism, open-air drug dealing, loitering by gang members, and prostitution can impose on neighborhoods. Overall, crime can be viewed as a neighborhood disamenity. One market that captures some of these neighborhood crime disamenities is the housing market.

During the 1990s, crime dropped dramatically throughout the United States. For example, homicide rates fell by 43 percent and the Federal Bureau of Investigation's (FBI) violent and property crime indexes fell by 34 and 29 percent respectively (Levitt (2004)). The largest improvements in crime occurred in metropolitan areas, especially in large cities. This dramatic crime drop came as a surprise. Levitt (2004) documents how leading experts were actually predicting an increase in crime even after the crime drop had begun. However, the socioeconomic fundamentals that were thought to drive crime were relatively stable over this same time period. This led Zimring (2007) to conclude his analysis of the 1990s crime drop by saying "Whatever else is now known about crime in America, the most important lesson of the 1990s was that major changes in rates of crime can happen without major changes in the social fabric (p. 206)." 
This paper exploits the unique crime drop that occurred in the 1990s to examine the link between crime and property values. From a research perspective one would like to conduct an experiment that adjusts crime rates across the U.S. to establish the causal impact of crime on property values. Although this ideal experiment is obviously impossible to conduct, certain features of the 1990s crime drop make it a type of natural experiment. These features include that the drop was large and unexpected, there was substantial variation in crime decreases within and across metropolitan areas, and the socioeconomic backdrop during this time period was not changing dramatically. Because this natural experiment takes place across the entire United States, we conform our analysis to a national setting. This allows us to take a much broader perspective on the relationship between crime and property values than the existing literature on the topic. Beginning with Thaler (1978), this small literature has focused only within a single metropolitan area and has typically relied on cross-sectional variation in crime and property values to obtain an estimate of some of the indirect costs of crime. ${ }^{1}$

Perhaps one of the reasons why no one has previously examined the relationship between crime and property values on a national scale is the difficulty associated with acquiring localized crime measures and corresponding information on housing prices throughout the United States. Furthermore, one must not only have crime and housing data at a local-level to exploit the crime drop that occurred in the 1990s, one must also have this data over time. In this project we have overcome this difficulty by compiling a comprehensive dataset of crime, property values, and socioeconomic characteristics from

\footnotetext{
${ }^{1}$ The cross-sectional literature includes Thaler (1978), Burnell (1988), Lynch and Rasmussen (2001), Bowes and Ihlanfeldt (2001) and Gibbons (2004). Several recent papers have moved beyond the crosssectional methodology by exploiting natural experiments within a metro area including: Schwartz et al. (2003) who looked at the crime decrease in New York City on real estate values, and Linden and Rockoff (2008) and Pope (2008) who have looked at the impact of sex offender movements on housing prices.
} 
1990 to 2000 at the zip code-level in nearly three thousand urban zip codes throughout the United States. The crime data comes from a combination of a commercial vendor's zip code-level estimates of crime and the FBI's Uniform Crime Reports. The housing data is also acquired from a commercial vendor who provides home price indices at the zip code-level following the Case-Shiller (1987) methodology. These exceptional data allow us to fully exploit the natural experiment of the crime drop during the 1990s to examine the relationship between crime and property values across the U.S.

The results we obtain are consistent with a strong relationship between changes in crime rates and property values. Using OLS, we estimate the effect of crime changes that occurred in a given zip code between 1990 and 2000 on the change in housing values that occurred over this same period. While controlling for Metropolitan Statistical Area (MSA) fixed effects, we find that a decrease in violent crime in a zip code by 100 per 10,000 of population is associated with an increase in the average housing value in that zip code by 3.4 to 4.3 percent. Given that the average zip code in our sample experienced a decrease of 30 violent crimes between 1990 and 2000, this result suggests an approximately one percent increase in property values for a zip code that experienced that average drop in crime relative to a zip code with no crime reduction. However, these figures mask the substantial heterogeneity that exists. The top decile of crime-reducing zip codes in our sample experienced a decrease in violent crimes of nearly 209 crimes. Thus, our model suggests an increase in housing values of $7.5-9.5 \%$ due to the reduction in crime for these select zip codes. These results are robust to the inclusion of zip codelevel controls for a variety of sociodemographic changes and to variables controlling for federal programs that also occurred in the 1990's that could act as potential confounders. 
Results for property crime changes are even larger. Our model suggests an increase in housing values by $14.5-19.5 \%$ for the top decile of zip codes in terms of property crime reduction. Estimating the relationship between percent changes in crime (as opposed to absolute changes) allows us to estimate elasticities of housing values with respect to crime. The OLS results with sociodemographic changes imply an elasticity with respect to violent crime of -0.15 and an elasticity with respect to property crime of -0.39 .

While we argue that our results are more credible than cross-sectional evidence, it is still primarily a correlational analysis. In an effort to distinguish between correlation and causation we take two additional steps in our investigation. First, we exploit annual housing value data to present a graphical analysis of the residuals from the regressions. These residuals are broken out by the quartiles of the 1990 violent and property crime levels. The temporal movement of housing price changes illustrated in this graphical analysis is consistent with the national trend in crime and suggests that our results are not explained by differences in pre-treatment trends. Second, we provide results from an instrumental variable (IV) procedure. We instrument changes in crime that took place in each zip code with a measure of the amount of crime that we would have expected to have taken place in that zip code based on the national crime trend. Specifically, we match each zip code to a zip code in another MSA with similar 1990 crime levels. In a first stage we can show that changes in the levels and percent of both violent and property crime that occurred between matched zip codes, are highly correlated even when including MSA fixed effects and the zip code-level controls. Our IV estimates are greater than or equal to the OLS results suggesting that the correlational results, if anything, may understate the true causal impact of crime rates on property values. 
The paper proceeds as follows. Section 2 provides additional detail on the 1990s crime drop. Section 3 describes our unique dataset that allows us to examine the crime and property value relationship. In section 4, we describe our empirical methodology and in section 5, we present the results. Finally, section 6 concludes the paper.

\section{The 1990s Crime Drop}

The drop in crime rates that occurred between 1993 and 2000 in the United States was historically unique. It provides a type of natural crime experiment that allows for an examination of the link between crime and property values. The crime drop was exceptional in several ways. First, the decrease in crime was large and swift. Second, the crime drop was unexpected. Third, the decrease in crime was largely unrelated to the underlying socioeconomic fundamentals that have been thought to be the drivers of crime fluctuations. In this section, we provide additional details on these unique aspects of the 1990s crime drop as background to our analysis on the link between crime and property values.

\subsection{Size and Timing of the Crime Drop}

The drop in crime rates from about 1993 to 2000 was dramatic. It was by far the largest and swiftest decrease in crime since modern record keeping of crime rates began in the United States. Documenting this crime drop relies on data from various sources that categorize crime in different ways. Crime comes in many different flavors. However, most research focused on national trends in crime has delineated crime into three categories: (i) homicides, (ii) violent crime other than homicides, and (iii) property 
crime. Here we graphically illustrate these three types of crime to provide the reader with a sense as to the size and timing of the crime drop.

The most reliable source of homicide information comes from the Vital Statistics System conducted by the National Center for Health Statistics (Wiersema, Loftin \& McDowall 2000). Information on homicides is collected around the U.S. by coroners and medical examiners during the course of their death investigations. Figure 1a shows the national trend in homicide rates per 10,000 people. As can be seen, homicides hovered at around 1 per 10,000 between 1975 and 1993 but then dropped to about .6 per 10,000 by the year $2000 .^{2}$

The National Crime Victimization Survey (NCVS) administered by the Bureau of Justice Statistics provides a measure of violent crime other than homicides. This information comes from a nationally representative sample of 87,000 households. The survey collects information on violent crimes (excluding homicides for obvious reasons) and property crimes suffered by individuals and households. Figure 1b shows the total violent crime per 10,000 people. The violent crimes included in the total are rape, robbery, aggravated assault and simple assault. From Figure $1 \mathrm{~b}$ it can be seen that the violent crime rate hovered between 450 and 500 during the 1975-1993 time period but then dropped to about 250 by the year 2000 .

For a per person calculation of property crimes we turn to the Uniform Crime Reports (UCR) administered by the Federal Bureau of Investigation. ${ }^{3}$ The UCR differs from the NCVS in that if a crime is not reported to a law enforcement authority, by

\footnotetext{
${ }^{2}$ There was a temporary, small jump in 2001, but this increase is fully explained by the terrorist attack on September 11, 2001.

${ }^{3}$ The NCVS also calculates property crime rates but does it per household instead of per person. Since the number of households does not change at the same rate each year as the population, it makes the trends difficult to compare.
} 
definition, it is excluded from the UCR. Property crimes included in the UCR are the same as the NCVS (burglary, theft, and motor vehicle theft) but are defined in a slightly different manner. ${ }^{4}$ Figure $1 \mathrm{c}$ graphs the UCR information on total property crime over the 1973 to 2005 time period used for the previous three figures. In Figure 1c, the now familiar crime drop from 1993 to 2000 once again manifests itself. From 1975 to 1993 property crimes hovered around the 5000 per 10,000 people mark, but between 1993 and 2000 they had dropped to about $3500 .^{5}$

Figures 1a through 1c, which rely on three important crime datasets typically used to analyze crime trends, make it clear that homicides, other violent crime, and property crime dramatically dropped from 1993 to 2000 . The percentage change in the crime drop for homicides between 1993 and 2000 for the U.S. was 40 percent. The percentage change in violent crime as measured by the NCVS over this same time period was $44 \%$. Property crime as measured by the UCR dropped by about $24 \%$.

\subsection{Expectations about Crime Before the Drop}

Given the swiftness of this drop and the magnitude, one would expect that crime experts would have foreseen the impending crime decrease in the early 1990s. This however was not the case. Levitt (2004) provides a nice discussion of the expectations that leading experts had in the early and middle part of the 1990s, about future crime trends. Most experts were predicting that crime would increase throughout the 1990s.

\footnotetext{
${ }^{4}$ For example, the UCR defines burglary as "the unlawful entry or attempted entry of a structure to commit a felony or theft," whereas the NCVS defines burglary as "the entry or attempted entry of a residence by a person who had no right to be there. This is because the NCVS which relies on surveys with victims does not want victims to determine criminal motives. Another difference between the UCR and the NCVS is that commercial property crimes are included in the UCR property crimes count but not in the NCVS.

${ }^{5}$ A similar crime drop using the UCR measures for violent crimes can be shown as well.
} 
One leading expert who was commissioned by the U.S. attorney general to write a report on crime trends in 1995, projected that youth homicides would rise by between 15 and 100 percent over the following decade even though they actually declined by approximately 50 percent (see Levitt 2004 for further discussion). Levitt (2004) concludes, "the crime decline was so unanticipated that it was widely dismissed as temporary or illusory long after it had begun.” (p.170).

\subsection{Relationship between the Crime Drop and Socioeconomic Fundamentals}

Before the 1990s crime drop, conventional wisdom among criminologists and economists was that socioeconomic fundamentals largely drive crime changes. This notion was primarily based on cross-sectional evidence that linked crime to a variety of socioeconomic factors such as one-parent families, population instability, income inequality and the prevalence of racial minorities. ${ }^{6}$ However, the 1990 s crime drop appears to fly in the face of this conventional wisdom. Using the 200 largest U.S. counties, Cook (2008) showed that the counties that improved in the socioeconomic characteristics that have been thought to drive crime were not much more likely to show drops in crime than other counties.

Cook (2008) concludes, "The 1990s experience - the large across-the-board reduction in crime without much progress in the socioeconomic fundamentals - is hopeful, in a way. It creates the possibility that crime rates can change dramatically, quite independently of changes in the fundamental socioeconomic conditions (p. 10)." In his comprehensive book on the subject, Zimring (2007) similarly concludes, "Whatever else is now known about crime in America, the most important lesson of the 1990s was

\footnotetext{
${ }^{6}$ Examples of this cross-sectional literature include Land, McCall and Cohen (1990) and Kelly (2000).
} 
that major changes in rates of crime can happen without major changes in the social fabric (p.206)." According to Zimring (2007), the fact that Canada saw a similar crime drop without many of the factors that have been attributed to causing the crime drop in the U.S. occurring, means that many of the causes of the crime drop are still unclear. While far from a perfect natural experiment, the size, timing, unexpectedness, and the relative stability of the "social fabric" within the United States help to make the 1990s crime drop a type of natural crime experiment useful for this study.

\section{Data}

One of the reasons why no one has previously examined the relationship between crime and property values on a national scale is the difficulty in acquiring localized crime measures and corresponding information on housing prices throughout the United States. To overcome this difficulty we have compiled three datasets on crime, property values, and socioeconomic and demographic controls. Each of these datasets spans the 1990 to 2000 timeframe at the geographic scale of zip code. In this section, we describe each data type in preparation for our empirical analysis.

\subsection{Crime Data}

The two primary sources of data on national crime that have been used by researchers in the past are the National Crime Victimization Survey (NCVS) administered by the Bureau of Justice Statistics and the Uniform Crime Reports (UCR) administered by the Federal Bureau of Investigation. As was described in section 2, the NCVS relies on a national survey of households and is only reported at the state and 
national levels. Therefore, it cannot be used to look at local crime rates. The UCR data, which collects information on crimes reported to law enforcement authorities, is reported at the scale of a law enforcement authority's jurisdiction. This can be as localized as a small rural town, or as large as an entire metropolitan city serviced by a single police department. The smallest geographic level by which the UCR is consistently reported is the county level.

For our analysis we want to exploit the variation in crime that occurs within counties over time. To do this we combine information from the UCR county-level data with a dataset purchased from CAP Index, Inc. to produce measures of crime changes in 1990 and 2000 at the zip code-level. CAP Index, Inc. specializes in providing objective measures of crime for specific sites and neighborhoods. ${ }^{7}$ CAP Index combines data from a variety of sources including police reports, UCR data, client loss reports, and offender and victim surveys to create a "crime score," for the same violent and property crime categories that are in the UCR at a local level. ${ }^{8}$ CAP Index then provides a crime score index that ranges from 0 to 2000 with 100 being the average score in the United States. ${ }^{9}$

A difficulty with the CAP Index data from the perspective of our analysis is that comparing the crime scores across time is not straightforward. If the level of crime were reduced in all zip codes in the U.S. by the same amount over time, then the difference in the CAP Index crime scores over time would be zero. This is because the crime scores only provide relative information about zip code-level crime in the U.S. at one point in

\footnotetext{
${ }^{7}$ CAP Index, Inc. provides crime forecasting models and loss mitigation solutions to 81 of the top U.S. Fortune 100 Companies.

${ }^{8}$ CAP Index can provide property specific information. See for example Garmaise and Moskowitz (2006) who use CAP Index, Inc. data in their analysis of bank mergers and crime.

${ }^{9}$ As a check on the validity of the CAP Index data relative to the more standard UCR data, we aggregate the CAP Index data to the county level and correlate this with the UCR data. The correlation between the total crime counts in the UCR and the total crime index value from CAP Index is . 44 .
} 
time. Homebuyers and sellers may react not only to the changes in relative crime over time, but also to changes in the levels of crime over time.

We want a zip code-level measure of crime that reflects actual crime rates as opposed to simply an index that does not account for changes in crime over time. To do this, we aggregate the CAP Index scores, weighting each zip code by its population, to the county-level for violent crimes and property crimes. ${ }^{10}$ We then regress UCR violent crimes and property crimes data separately on the corresponding CAP Index crime scores (and polynomials of the crime scores) for 1990 and 2000. The resulting "crime coefficients" provide a measure of the crime levels in the UCR data that can be explained by the CAP Index crime scores. Thus, the crime coefficients can be used to weight and aggregate the CAP Index crime scores to provide an estimate of the actual crime rate in each zip code. Table 1 summarizes the resulting violent and property crime rates by zip code for the 2922 zip codes that make up our final sample. The table illustrates that the average decrease in violent and property crime that occurred in these zip codes between 1990 and 2000 was approximately $10 \%$ and $20 \%$, respectively. ${ }^{11}$ The standard deviations provided for these coefficients suggest that the variation in the change in crime that occurred was substantial both between and within MSAs.

\subsection{Property Value Data}

\footnotetext{
${ }^{10}$ Although homicides are a good national barometer of crime, they are rare enough at a localized level that it is difficult to use homicides as a crime indicator on its own. Therefore, we follow the convention made by others studying crime (i.e. Cullen and Levitt 1999) and focus on total violent crimes (which includes homicides) and property crimes.

${ }^{11}$ These percent decreases are smaller than the national decrease illustrated in Section 2. This is in large part due to the summary statistics giving equal weight to each zip code when calculating the mean crime reduction. Since, higher crime zip codes tend to have larger populations, the average over zip codes is mechanically smaller than the national average.
} 
The property value data used in our analysis is Fiserv's Case-Shiller Index (CSI), produced at the zip code level. These indices are estimated using arithmetic weighting of repeat sales (Shiller 1991) which is a variation of the Case and Shiller (1987) weighted repeat sales methodology. Housing prices of homes that have sold at least twice are collected from primarily metropolitan areas across the country. Each of these transactions has been screened to ensure that they meet criteria such as having been an arms length transaction. There are approximately 3,000 zip code-level CSI's that have been consistently estimated each year from 1990 to 2000 . These 3000 zip codes are found in 22 states, 51 metropolitan statistical areas (MSA), and account for approximately one fourth of the U.S. population. As can be seen in Table 1, we normalize the index such that each zip code has an index score of 100 in 1990. Between 1990 and 2000, the average increase in housing prices was about $45 \%$ with substantially more variation across MSAs relative to within MSAs. One of the advantages of this data relative to median sales price measures of changes in housing values over time (i.e. selfreported housing values given in the decennial census), is that it is not affected by the mix of properties that are sold in a given time period. Furthermore, the indexes are not affected by differences in average housing quality across zip codes. The CSI is widely considered the most accurate measure of single-family home price changes in the areas that it covers. Surprisingly, the zip code-level indices have been rarely used in academic research, and to the best of our knowledge, the full set of available zip codes has never before been used in the economics literature. ${ }^{12}$

\footnotetext{
${ }^{12}$ The only exception that we are aware of is Bui and Mayer (2003) which uses all the Case-Shiller zip codes in Massachusetts.
} 


\subsection{Control Variable Data}

Although according to Cook (2008), socioeconomic and sociodemographic fundamentals appear largely unrelated to the changes in crime that occurred throughout the 1990s, it still may be important to control for these factors, especially at a sub-MSA level. Our economic and demographic information was acquired from Geolytics's "Normalized Data" product. Because census geographic boundaries often change, it can be difficult to compare census information over time. Geolytics' normalized data provides information from the 1970, 1980, and 1990 and 2000 censuses in a temporally consistent way by weighting previous census information to the 2000 census geographies. We obtained from Geolytics socioeconomic and sociodemographic information from the 1990 and 2000 censuses. We also obtained information on three Federal programs whose impact may have also been felt in the mid-1990's. These three programs were the creation of "Empowerment Zones" and "Renewal Communities" as well as the creation of additional low income housing units from the "Low Income Housing Tax Credit" program. Each of these data was obtained directly from public use data provided by the Department of Housing and Urban Development (HUD). Table 1 shows summary measures of the socioeconomic, demographic and Federal program variables used in our analysis and how they have changed over time.

\section{Empirical Strategy}

\subsection{Hedonic Pricing Method}

The hedonic pricing method has become an important tool used by economists to estimate household valuations for local amenities such as crime. Under this method, it is 
argued that economic agents choose a place of residence by making informed tradeoffs between housing characteristics and various local amenities. Housing values (a measure of revealed preference) are then used to isolate the "implicit price" of a particular housing attribute or neighborhood characteristic. Early applications of this technique included attempts to understand the value of air quality (e.g. Ridker and Henning (1967)), the value of schools (e.g. Kain and Quigley (1970)), and as referenced earlier, the value of crime (e.g. Thaler (1978)).

A primary concern with the implementation of the hedonic pricing method in the housing market is omitted variable bias. Unobserved factors that are spatially correlated with the amenity of interest can lead to inconsistent estimates of implicit prices. This concern is often at its highest level when performing cross-sectional analyses. For example, in the context of crime, it is not hard to imagine that areas with high levels of crime may differ from their counterparts in labor market conditions, school quality, environmental features, and other important amenities. To the extent that these correlates of crime are not available to be controlled for in a regression analysis, estimates of the effect of crime on housing will be biased. A panel design has the potential to ameliorate the issue of omitted variable bias. The geographic fixed effects eliminate unobserved crime correlates that are time-invariant. However, to the extent that unobserved factors change at the same time as crime changes, omitted variable bias may continue to plague panel coefficient estimates.

The empirical importance of omitted variable bias in hedonic models has recently been highlighted by Black (1999), Chay and Greenstone (2005), and Pope (2008) among others. These paper have applied quasi-random experimental procedures to urban and 
environmental valuation questions that likely suffer from omitted variable bias in a crosssectional analysis. The work presented in this study builds off this literature in the construction of an identification strategy to understand the impact of crime on housing prices. Specifically, we exploit the plausibly exogenous variation in crime caused by the large crime decrease in the 1990s to analyze the impact of crime on housing values.

The most basic hedonic price specification that we employ takes the following form:

$$
\Delta \text { CaseShille }_{\text {rIndex }}^{i j}=\alpha+\beta\left(\Delta_{\text {CrimeRate }}{ }_{i j}\right)+\gamma \Delta X_{i j}+\varepsilon_{i j}
$$

The change in the Case Shiller Index between 2000 and 1990 for each zip code $i$ in MSA $j$ is represented as a linear function of the change in crime rate (violent or property) that occurred in that zip code between 2000 and 1990, the change in a variety of control variables $\left(\Delta X_{i j}\right)$, and a random error term. It is worth noting again that we do not need to control for physical housing characteristics because the Case Shiller Index is based on repeat sales for homes where physical housing characteristics are differenced away.

\subsection{Critiques of Identification Strategy}

There are several critiques of the identification strategy specified by Equation (1) that we are able to address. First, our analysis uses data across the US to identify the impact of crime on housing. The hedonic literature, however, suggests that housing markets are typically at the level of a city or smaller (see Palmquist (2005) for a discussion) suggesting that treating the country as one large housing market may be naïve. Furthermore, MSA-level shocks may occur which differentially affect cities with 
high levels of crime relative to cities with low levels of crime. Fortunately, we have constructed a dataset with housing prices and crime at the zip code level. Thus, we have the luxury of running our model between and within MSAs. We present estimates from specifications with and without the MSA fixed effects and highlight the results using the fixed effects due to the concerns mentioned and because coefficients are estimated with more precision.

A second critique involves the structure of the relationship between crime rate changes and housing values. As presented, this specification suggests that absolute changes in crime rates affect housing values. An alternative specification would allow for percent changes in crime rates to impact housing values. Our intuition is that using absolute changes is a more accurate model - a drop in the crime rate by $50 \%$ in a highcrime zip code in New York, for example, should have a larger impact on housing values in that zip code than a drop in the crime rate by $50 \%$ in a small town that had very little crime to begin with. However, we present results using both absolute and percent changes in crime rates for completeness.

Looking at equation (1), one might ask why we are doing a difference regression over a 10 -year period rather than smaller time differences. While we have access to the Case Shiller Index annually, we do not have yearly crime data at the zip-code level. Thus due to data limitations, we are unable to estimate the impact of year-to-year changes in crime rates on year-to-year changes in housing values. While our regression framework does not allow for an annual analysis, we provide graphical evidence in the next section that exploits the available, annual changes in house prices, to test for differences in pretreatment trends, and explore how crime may affect housing prices from year-to-year. 
A final critique of Equation (1) is that even with MSA fixed effects and the large drop in crime that occurred in the 1990s, this specification might still fail to identify a causal relationship between crime and property values due to omitted variable bias. Without explicit randomization, we are not able to fully address this concern. However, we can improve upon simple OLS estimates. Equation (1) relies on two sources of variation in crime rate changes in order to identify the effect of crime on property values. The first source of variation is a result of differential impacts that the national trend in crime during the 1990s had on zip-code level crime rates. However, mixed in with this variation are changes in crime rates that did not occur because of the national trend. For example, a handful of zip codes actually experienced an increase in crime rates through the 1990s. The variation that comes from this type of crime rate change clearly has the potential to be endogenous and provides the motivation for an instrumental variables strategy.

\subsection{Instrumental Variables Strategy}

We propose an instrumental variables strategy that allows us to isolate the variation in crime rate changes that occurred due to the national drop in crime during the 1990s. The basic intuition for this identification is that while the crime decrease during the 1990s was largely ubiquitous, certain areas were particularly affected. Specifically, high-density areas with a large amount of crime at the start of the 1990s experienced a greater decrease in crime (both in absolute and percentage terms) than their counterparts. For example, Levitt (2004) noted that the violent crime rates between 1991 and 2001 decreased by $36.7 \%$ within MSAs (where crime rates were initially higher) and by only 
$2.9 \%$ in rural areas. Thus, the drop in crime during the 1990 s had a very heterogeneous effect across space.

In order to isolate the impact of the national trend on a given zip code, we instrument each zip code's crime rate change with the crime rate change that occurred over the same period for a "similar" zip code in a different MSA. For example, the crime decrease between 2000 and 1990 that occurred in a dense, high-crime zip code in New York can be instrumented with the crime drop that occurred in a zip code in Los Angeles with similar 1990 crime levels. Thus, variation in crime rate changes that were abnormal relative to other MSAs during the 1990s are not picked up by the instrument while changes that matched the general trend are.

The exact instrumental variables method we perform is as follows. We execute a nearest-neighbor matching algorithm that identifies for each zip code, a zip code from a different MSA that is the closest match based on 1990 crime rates. This matching is a simplification of the type of matching that has frequently been used by researchers attempting to match observations from a treatment group with a control group in order to make causal inference (Rosenbaum and Rubin, 1983; Hirano, Imbens, and Ridder, 2001). Our strategy is unique in that we use the nearest neighbor match to identify the out-ofMSA candidate to serve as an instrument zip code rather than as a control zip code. Once we obtain the match for each zip code, we instrument the change in crime that occurred in a zip code with the change in crime that occurred over the same time for its matched zip code. ${ }^{13}$ While Equation (1) provides the simplest specification that we employ, the

\footnotetext{
${ }^{13}$ Rather than matching solely on 1990 levels of crime, we could conceivably match zip codes on a host of 1990 census characteristics (e.g. percent black, percent unemployed, etc.). We choose to match only on 1990 crime levels for two key reasons. First, 1990 levels of crime predict better than any other variable changes in crime between 2000-1990. Thus, matching on other variables reduces the overall fit of the first
} 
following equation (which includes MSA fixed effects and indicates the IV strategy) is the most detailed specification in the paper:

$$
\left.\Delta \text { CaseShille rIndex } i j=\alpha_{i}+\beta\left(\Delta \text { CrimeRate }{ }_{i j} \text { (Instrument ed }\right)\right)+\gamma \Delta X_{i j}+\varepsilon_{i j}
$$

A natural question is whether we would expect our instrumental variables method to increase or decrease the estimates of crime on property values relative to simple OLS. We would expect the results to be attenuated to the extent that the IV strategy eliminates endogenous crime reductions that were accompanied by zip-code specific improvements in neighborhood amenities. However, if a significant fraction of the changes in crime that occurred that did not follow the national pattern were a result of mismeasurement or misreporting of crimes, then we would expect OLS estimates to contain attenuation bias and the instrumental variables results should be larger. ${ }^{14}$ The relative incidence of endogeneity and measurement error will determine the relative size of the OLS and IV estimates.

The instrumental variables strategy as outlined above is not without flaws. Given that the identification is based on an event-study-like methodology, a key assumption is that a shock did not occur around 1994 that differentially affected high and low crime areas. While we attempt to control for several potential shocks (unemployment rate

\footnotetext{
stage. Second, matching on unemployment rates, population density, or other variables opens up the possibility of shocks that differentially affect certain types of zip codes to bias our estimates. Using the more parsimonious matching algorithm reduces the number of potential shocks that might affect our results.

${ }^{14}$ See for example the discussion of the tradeoff between endogenity and measurement error in the returnsto-education literature (Card, 2001).
} 
changes, empowerment and renewal community zones, etc.) the absence of an unobservable shock is a necessary condition for unbiased estimation. ${ }^{15}$

\section{Results}

\subsection{Correlations and OLS Results}

Figures $2 \mathrm{a}$ and $2 \mathrm{~b}$ use the raw data to illustrate the relationship between changes in property values and changes in violent and property crime between 2000 and 1990 . Exploiting both the within and between MSA variation in zip-code levels of crime and property values, these scatter plots suggest no strong relationship between housing price changes and changes in violent or property crimes. However, using the same axis scales, Figures $2 \mathrm{c}$ and $2 \mathrm{~d}$ present the relationship between changes in crime and residual changes in property values which rely exclusively on within-MSA variation. Looking within each MSA dramatically reduces the amount of noise and results in a strong, negative relationship between the crime and property value changes.

A more rigorous analysis of the relationship between changes in crime and property values is presented in Table 2. Panel A provides OLS regression estimates (see Equation (1)) of the impact of violent and property crime changes on changes in housing values. In harmony with the findings in Figure 2, Columns (1) and (4), which do not include MSA fixed effects, suggest a small and insignificant effect of violent and property crime changes on housing values. The more reliable estimates that control for

\footnotetext{
${ }^{15}$ One might argue that the economics literature has provided several potentially exogenous instruments for that could be used such as lead reduction (Reyes, 2007), abortion laws (Donohue and Levitt, 2001), or drug busts (Dobkin and Nicosia, forthcoming). However, all of these studies provide potentially exogenous crime variation at the state-level or higher. As will be shown in the results section, because of the large changes that take place in housing prices across states and MSAs, we are only able to identify an impact of crime changes on property values when looking within an MSA. Thus, only an instrument for crime that works within an MSA could provide appropriate identification.
} 
MSA fixed effects are presented in Columns (2) and (5). These estimates, which indicate a negative relationship between crime changes and property value changes, are statistically significant and economically large. The coefficient in Column (2) suggests that a decrease in violent crimes by 100 per 10,000 people is associated with an increase in property values of $3.6 \%$. The average zip code in our sample experienced a decrease in their violent crime rate by approximately 30 crimes between 1990 and 2000 suggesting an average housing price change of about $1 \%$ due to changes in violent crime over this period. However, this average masks the large amount of heterogeneity that existed in crime changes. For example, the $10 \%$ of zip codes with the largest crime decreases had an average violent crime reduction of 209 crimes per 10,000. Thus, for these zip codes, our model suggests that the decrease in crime between 1990 and 2000 resulted in an increase in housing values of nearly 7\%. The coefficient estimate in Column (5) on property crimes can be interpreted in a similar way and suggests even larger results. The effect of the average zip code reduction in property crimes between 1990 and 2000 (711) is associated with a $5.6 \%$ increase in property values. The $10 \%$ of zip codes with the largest property crime reductions experienced an average increase in housing values of 14.3\%. The specifications in Columns (3) and (6) of Table 2 include zip-code level controls in addition to MSA fixed effects. The coefficient on both violent crime changes and property crime changes in these specifications are even larger in absolute value (by approximately $30 \%)$.

Panel B of Table 2 provides an analogous analysis to Panel A, but tests the relationship between percent changes in violent and property crimes on changes in housing values. Once again, we find a negative relationship between crime and housing 
changes that becomes even stronger when including MSA fixed effects and when including controls at the zip-code level. The coefficient in Column (3) can be interpreted as finding that a decrease in violent crime rates by $10 \%$ results in an increase in property values by $1.5 \%$.

\subsection{Dynamics of Housing Price Changes}

Using the annual Case Shiller housing data, we are able to provide a more complete picture of the results presented in Figure 2 and Table 2 by showing the timing of the housing price changes that occurred between 1990 and 2000. To do this, we obtain housing price residuals each year by regressing the Case Shiller Index for each zip code on MSA*year dummy variables. The resulting residuals provide a representation of the unexplained change in housing prices that occurred for each year between 1990 and 2000 for each zip code. Figures $3 \mathrm{a}$ and $3 \mathrm{~b}$ graph these residuals by quartiles of violent and property crime changes. Looking at Figure $3 \mathrm{a}$, unexplained housing prices changed very little at the beginning of the 1990s between the zip codes that experienced the largest decrease in crime between 1990 and $2000\left(75\right.$ th- $100^{\text {th }}$ percentile) and zip codes that experienced the smallest decrease in crime $\left(0-25^{\text {th }}\right.$ percentile). In fact, the change in unexplained housing values between 1990 and 1994 was essentially zero across these groups. However, starting in about 1994 and going up and through 2000, housing prices began to diverge between zip codes that experienced the largest change in crime relative to their counterparts. Similar dynamics are shown in Figure 3b, which cuts zip codes into quartiles based on changes in property crime between 1990 and 2000. This pattern of housing price changes is very consistent with the national trend in crime that occurred 
and illustrates that the result we find in Table 2 are not explained by differences in pretreatment trends.

\subsection{Results}

We use an instrumental variable strategy discussed in section 4.3 to estimate the impact of crime changes that are solely a result of the national trend on changes in housing values. Table 3 provides the first stage results by regressing the change in crime that occurred between 1990 and 2000 for a given zip code on the change in crime that occurred in the zip code from a different matched MSA, which matching was based on 1990 crime levels. As expected, changes in crime that occurred between matched zip codes are highly correlated. This is true with both violent and property crime, percent and level changes, and when including MSA fixed effects and other controls. In fact, changes in crime that occurred in a matched zip code explain anywhere from $15 \%$ to $80 \%$ of the variation in crime decreases that we find suggesting that the instrument has ample statistical power.

Table 4 presents the instrumental variable results. Once again, Panel A provides the results when using absolute changes in violent and property crime while Panel B uses percent changes in crime. After controlling for MSA fixed effects, we again find a strong negative association between crime rates and property values that become even larger when including zip-code-level controls. It is informative to compare the IV results that are presented in Table 4 with the OLS results from Table 2. The IV coefficients on violent crime changes for both absolute levels and percent changes are 20-60\% larger than the OLS coefficients. For property crimes, the IV coefficients are $0-10 \%$ larger. As 
discussed in the empirical strategy section, we attribute the increase in coefficient size to measurement error in the crime data. Using a similar interpretation of the coefficients, Column (3) of Table 4 suggests that a drop in violent crime by 100 per 10,000 people is associated with a $5.5 \%$ increase in housing values. For the $10 \%$ of zip codes with the largest violent crime reduction, we estimate that the effect of this reduction was a $12.1 \%$ increase in property values.

\subsection{Alternative Specifications and Robustness Checks}

Several alternative specifications and robustness checks may provide additional clarity and confidence to the results presented in the previous sections. Here, we consider two such alternative specifications.

The results presented in Tables 2-4 regress the change in property values on violent and property crimes separately. Due to the large degree of correlation between violent and property crime changes (correlation $=.76$ ), it is difficult to confidently estimate the impact of violent and property crimes separately on housing values. The results presented in Tables 2-4 should be interpreted as the impact of changes in overall criminal activity in a zip code (as reflected by either violent or property crime changes) on housing values. However, we provide here - in Appendix Table 1 - analogous results to Table 2 when jointly identifying the impact of violent and property crimes on housing values. When including both violent and property crime in the regression, the coefficients on violent crime are reduced substantially while those on property crime tend to be robust (although it depends to some degree on whether levels or percent changes are used). This suggests that property values are more reactive to changes in property crimes 
than violent crimes. Alternatively, however, these effects may result from the fact that more property crimes take place in each zip code, which causes the property crime measure to contain less noise than the violent crime measure.

As mentioned in the empirical strategy section, the event-study research design that we employ in this paper requires that no shock occurred around 1994 that differentially affected high and low crime zip codes. The graphical analysis that we present as well as the robustness of our results to the inclusion of various MSA and zipcode level controls helps to alleviate the concern of endogenous findings. One worry, however, may be that changes took place in the 1990s that differentially affected zip codes with high housing values relative to zip codes with low housing values. For example, evidence suggests that when overall housing prices increase, the distribution of housing prices also change - low-value houses increase in price by more than high-value houses (Case and Mayer, 1995). We are interested in identifying the impact of a change in crime, not a trending result based on changes in the distribution of house prices. Appendix Table 2 provides analogous results to Table 2, while controlling for the 1990 median house price value in each zip code. ${ }^{16}$ The coefficient on the 1990 median house value suggests that - within MSAs - homes that had higher 1990 house values actually increased in value over the 1990s. More importantly for this analysis, we find only minor changes to the estimates of the effect of crime on housing values after adding the additional control.

\footnotetext{
${ }^{16}$ Median housing values by zip code were obtained from the 1990 decennial Census.
} 


\section{Conclusions}

This paper examines the link between crime and property values. Exploiting the dramatic, nationwide decrease in crime that occurred in the $1990 \mathrm{~s}$, we estimate a significant negative relationship between changes in crime rates and property values. The magnitude of the crime impact on property values is quite striking. The estimated elasticities of housing values with respect to crime range from -0.15 to -0.35 . These effects suggest that the top decile of zip codes in terms of crime reduction in our sample saw property value increases of 7-19\% between 1990 and 2000. Our findings hold whether we use simple panel data methods, use an instrumental variables estimator, or if we control for other socioeconomic factors or government projects that also occurred in the 1990's that could act as potential confounders. The findings are also consistent for both violent and property crimes, and for whether we use changes in the levels or changes in the percent of crime as our measure of crime change. The graphical analysis of the residuals and the similarity of the IV results suggests that that causality runs from decreasing crime to increasing property values.

Using the 1990 decennial census we calculate the average property values for the nearly 3000 zip codes used in our analysis as well as the average property values in the zip codes that are in the top decile of violent and property crime. ${ }^{17}$ Using these 1990 average property values as well as the average decline in violent crime across zip codes (approximately 30), we estimate that the crime decrease translated into an average gain of around $\$ 2,000$ per house. However, in the top decile of zip codes in terms of violent crime, the average violent crime decrease was around 209. Our estimates suggest that in

\footnotetext{
${ }^{17}$ Average housing values in all 2922 zip codes is approximately $\$ 160,000$, in the 292 zip codes in the top decile for violent crime it is approximately $\$ 122,000$, and the 292 zip codes in the top decile for property crime average housing values are approximately $\$ 144,000$.
} 
these zip codes, the housing price gain from decreased crime was closer to $\$ 11,000$ for each house. The average price gains were even larger when calculated looking at changes in property crime. These estimates would suggest per house property value gains of between $\$ 11,000$ for all zip codes and between $\$ 20,000$ and $\$ 27,000$ for houses in the top decile of property crime.

The analysis presented in this paper is the first attempt to estimate the impact of crime on housing values at the national level. This paper also contributes to the literature on the rise and fall of urban areas and cities. ${ }^{18}$ Urban areas have for many years been in decline. However, during the 1990's many urban areas have staged a comeback. Policymakers and city officials are keenly interested in the reasons for this resurgence. One factor that has been hypothesized to have contributed to the recent resurgence of urban areas was the dramatic drop in crime during the 1990's that occurred in these urban areas. The results in this paper lend support to this theory by documenting the relationship between crime and property values. Thus this work supports the view that policymakers and city officials concerned with urban growth should make crime prevention an important priority. Additional work on the relationship between city efforts to reduce crime, the role of specific crimes on property values and the magnitude of other externalities stemming from crime and its influence on property values represent exciting avenues for future research.

\footnotetext{
${ }^{18}$ See for example Glaeser and Gyourko (2005) and Glaeser and Gottlieb (2006).
} 


\section{References}

Anderson, D. A. (1999). "The Aggregate Burden of Crime." Journal of Law and Economics 42(2): 611-642.

Black, S. (1999). "Do Better Schools Matter? Parental Valuation of Elementary Education." Quarterly Journal of Economics 114(2): 577-599.

Bowes, D. R. and K. R. Ihlanfeldt (2001). "Identifying the Impacts of Rail Transit Stations on Residential Property Values." Journal of Urban Economics 50(1): 125.

Bui, L. T. M. and C. J. Mayer (2003). "Regulation and Capitalization of Environmental Amenities: Evidence from the Toxic Release Inventory in Massachusetts." Review of Economics and Statistics 85(3): 693-708.

Burnell, J. D. (1988). "Crime and Racial Composition in Contiguous Communities as Negative Externalities: Prejudiced Household's Evaluation of Crime Rate and Segregation Nearby Reduces Housing Values and Tax Revenues." American Journal of Economics and Sociology 47(2): 177-193.

Card, D. (2001). "Estimating the Return to Schooling: Progress on Some Persistent Econometric Problems." Econometrica, 69(5): 1127-1160.

Case, K. E. and R. J. Shiller (1987). "Prices of Single-Family Homes since 1970: New Indexes for Four Cities." New England Economic Review (September/October): 45-56.

Case, K.E. and C.J. Mayer (1995). "The Housing Cycle in Eastern Massachusetts: Variations among Cities and Towns." New England Economic Review 0(0): 24 40.

Chay, K. and M. Greenstone (2005). "Does Air Quality Matter? Evidence from the Housing Market." Journal of Political Economy 113(2): 376-424.

Cook, P. J. (2008). "Assessing Urban Crime And Its Control: An Overview." National Bureau of Economic Research Working Paper Series No. 13781.

Cullen, J. B. and S. D. Levitt (1999). "Crime, Urban Flight, and the Consequences for Cities." The Review of Economics and Statistics 81(2): 159-169.

Dobkin, C. and N. Nicosia (forthcoming). "The War on Drugs: Methamphetamine, Public Health and Crime." American Economic Review.

Donohue, J. and S. D. Levitt (2001). "Legalized Abortion and Crime." Quarterly Journal of Economics 116(2): 379-420.

Garmaise, M. J. and T. J. Moskowitz (2006). "Bank Mergers and Crime: The Real and Social Effects of Credit Market Competition." The Journal of Finance 61: 495538.

Gibbons, S. (2004). "The Costs of Urban Property Crime." The Economic Journal 114: F441-F463.

Glaeser, E.L. and J. Gyourko (2005). "Urban Decline and Durable Housing.” Journal of Political Economy 113(2): 345-375.

Glaeser, E.L. and J.D. Gottlieb (2006). "Urban Resurgence and the Consumer City." Urban Studies 43(8): 1275-1299.

Hirano, K., Imbens, G., and G. Ridder (2003). "Efficient Estimation of Average Treatment Effects using the Estimated Propensity Score.” Econometrica 71: 11611189. 
Kain, J.F. and J.M. Quigley (1970). "Measuring the Value of Housing Quality.” Journal of the American Statistical Association 65: 532-548

Kelly, M. (2000). "Inequality and Crime." The Review of Economics and Statistics 82(4): 530-539.

Land, K. C., P. L. McCall, et al. (1990). "Structural Covariates of Homicide Rates: Are There Any Invariances Across Time and Social Space?" The American Journal of Sociology 95(4): 922-963.

Levitt, S. D. (2004). "Understanding Why Crime Fell in the 1990s: Four Factors that Explain the Decline and Six that Do Not." The Journal of Economic Perspectives 18: $163-190$.

Linden, L. and J. E. Rockoff (2008). "Estimates of the Impact of Crime Risk on Property Values from Megan's Laws." The American Economic Review 98(3): 1103-1127.

Lynch, A. K. and D. W. Rasmussen (2001). "Measuring the Impact of Crime on House Prices." Applied Economics 33(15): 1981 - 1989.

Pope, J. C. (2008). "Fear of Crime and Housing Prices: Household Reactions to Sex Offender Registries." Journal of Urban Economics 64(3): 601-614.

Palmquist, R.B. (2005). "Property Value Models." Handbook of Environmental Economics, edited by Karl-Göran Mäler and Jeffery R. Vincent. Amsterdam: North-Holland.

Ridker, R.G. and J.A. Henning (1967). "The Determinants of Residential Property Values with Special Reference to Air Pollution." Review of Economics and Statistics 49(2): 246-257.

Reyes, J. W. (2007). "Environmental Policy as Social Policy? The Impact of Childhood Lead Exposure on Crime," B.E. Journal of Economic Analysis and Policy 7:1 (Contributions).

Rosenbaum, P.R. and D.B. Rubin (1983). "The Central Role of the Propensity Score in Observational Studies for Causal Effects." Biometrika 70: 41-55.

Schwartz, A. E., S. Susin, et al. (2003). "Has Falling Crime Driven New York City's Real Estate Boom?" Journal of Housing Research 14(1): 101-135.

Shiller, R. J. (1991). "Arithmetic Repeat Sales Price Estimators." Journal of Housing Economics 1(1): 110-126.

Thaler, R. (1978). "A Note on the Value of Crime Control: Evidence from the Property Market." Journal of Urban Economics 5(1): 137-145.

Wiersema, B., C. Loftin, et al. (2000). "A Comparison of Supplementary Homicide Reports and National Vital Statistics System Homicide Estimates for U.S. Counties." Homicide Studies 4(4): 317-340.

Zimring, F. E. (2007). The Great American Crime Decline. New York, Oxford University Press. 
Figure 1. U.S. Homicide, Violent Crime, and Property Crime Rate (1975 - 2005)

A. U.S. Homicide Rate (National Center for Health Statistics)

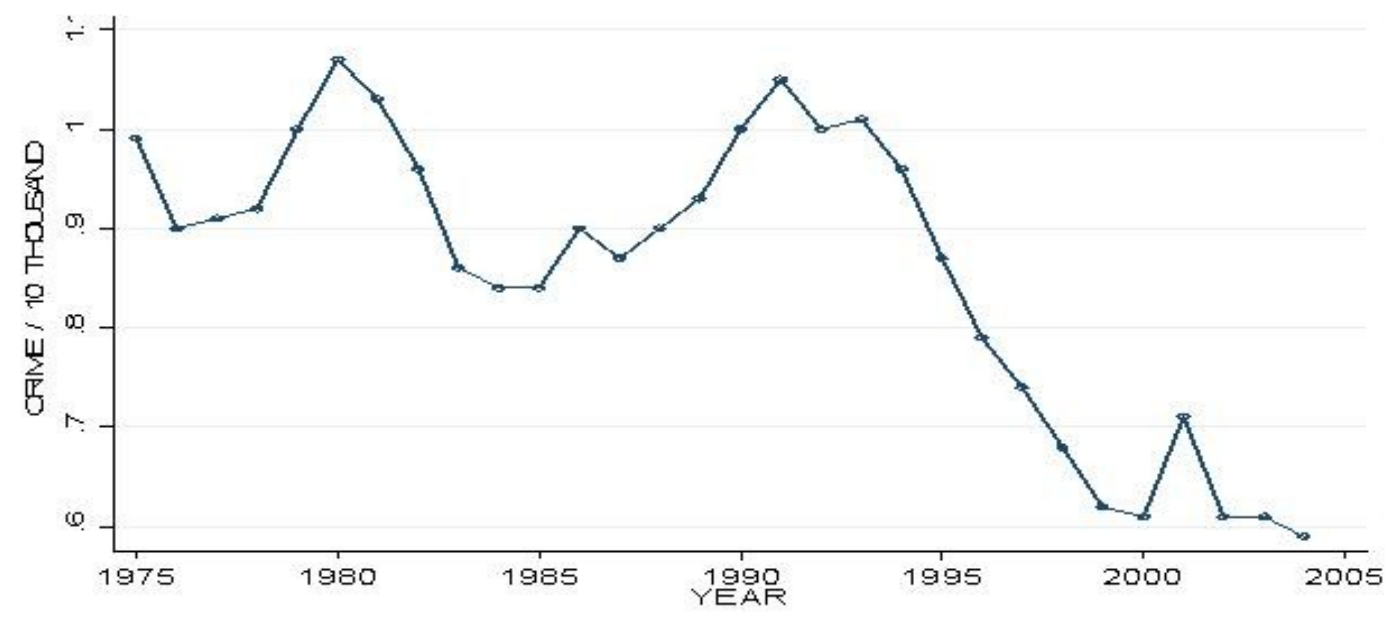

B. U.S. Violent Crime Rate (National Crime Victimization Survey)

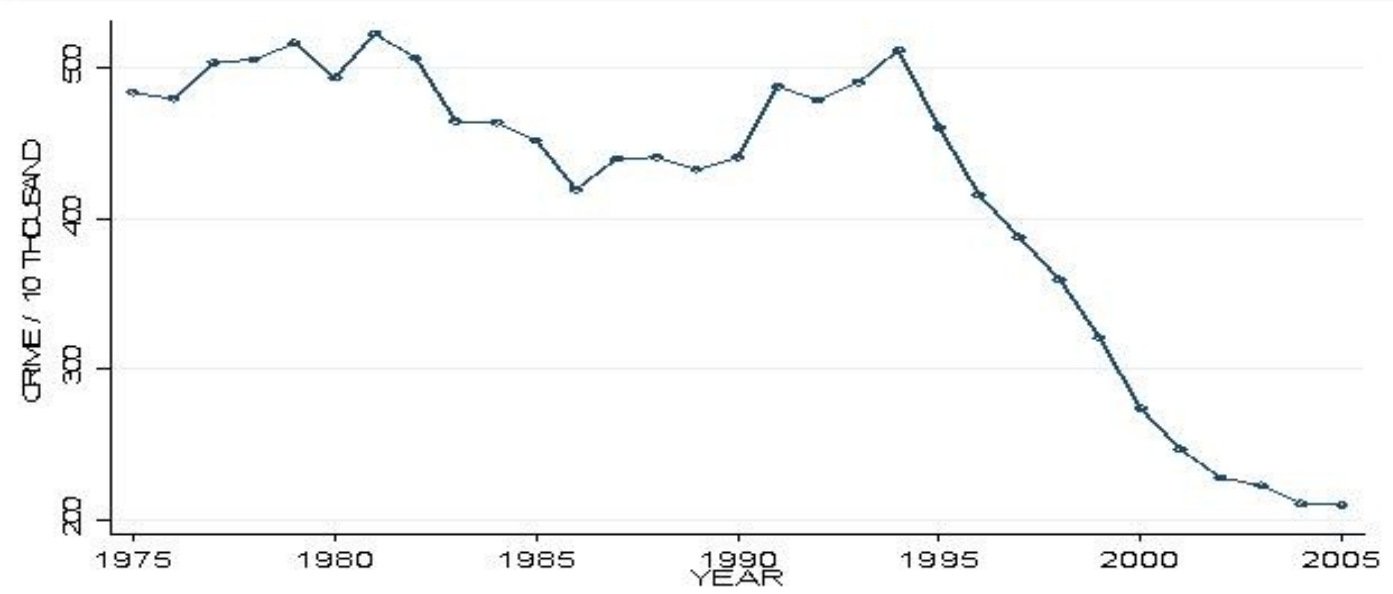

C. U.S. Property Crime Rate (Uniform Crime Reports)

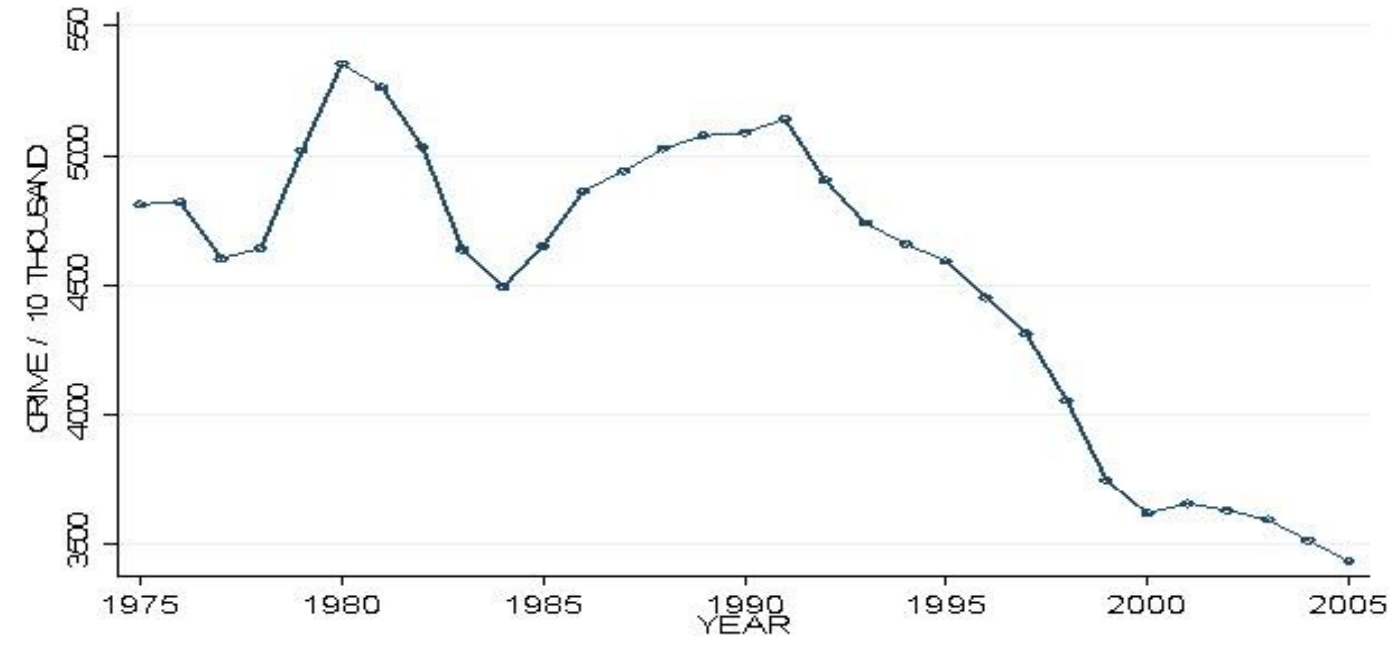

Notes: Homicide, violent, and property crime rates per 10,000 population are presented in Panels A, B, and C, respectively. The series from 1975 to 2005 are presented for each crime measure. Data for each crime measure were obtained from the indicated data source in each Panel header. 
Figure 2. Relationship between change in crime rates and change in housing values (2000-1990)

A. Violent Crime - Between and Within Variation

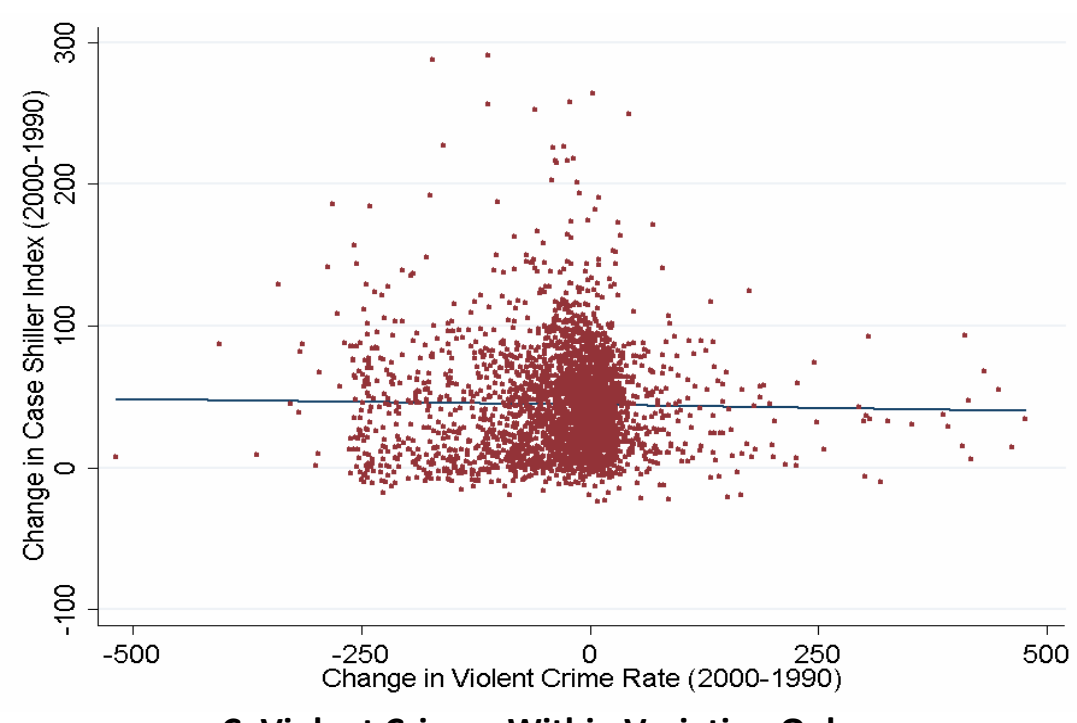

C. Violent Crime - Within Variation Only

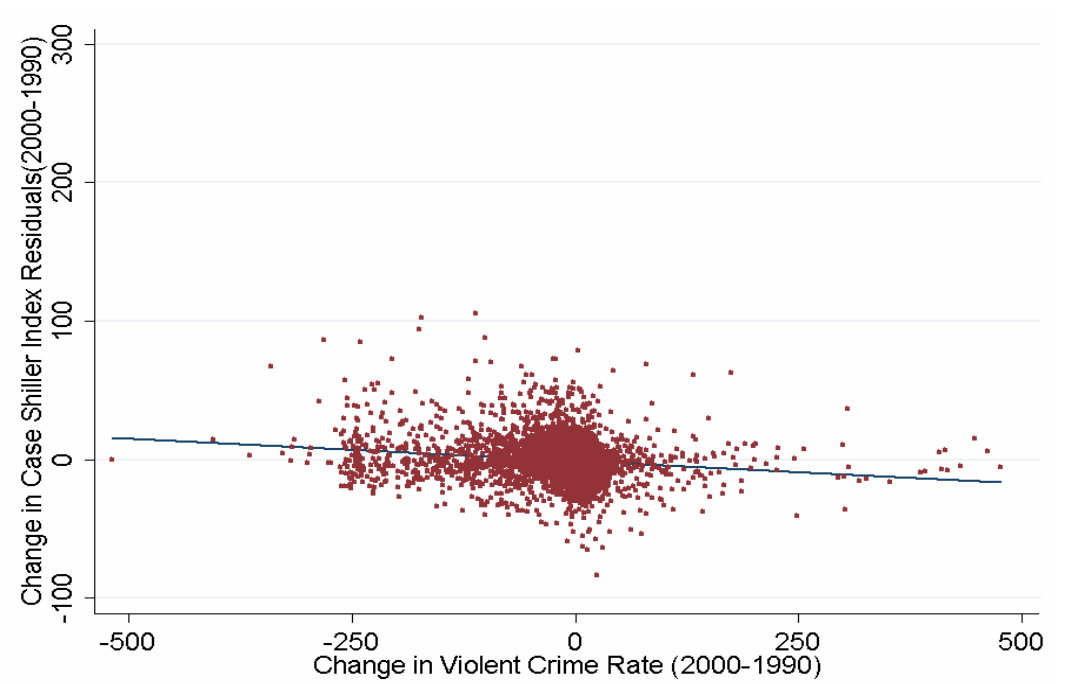

B. Property Crime - Between and Within Variation

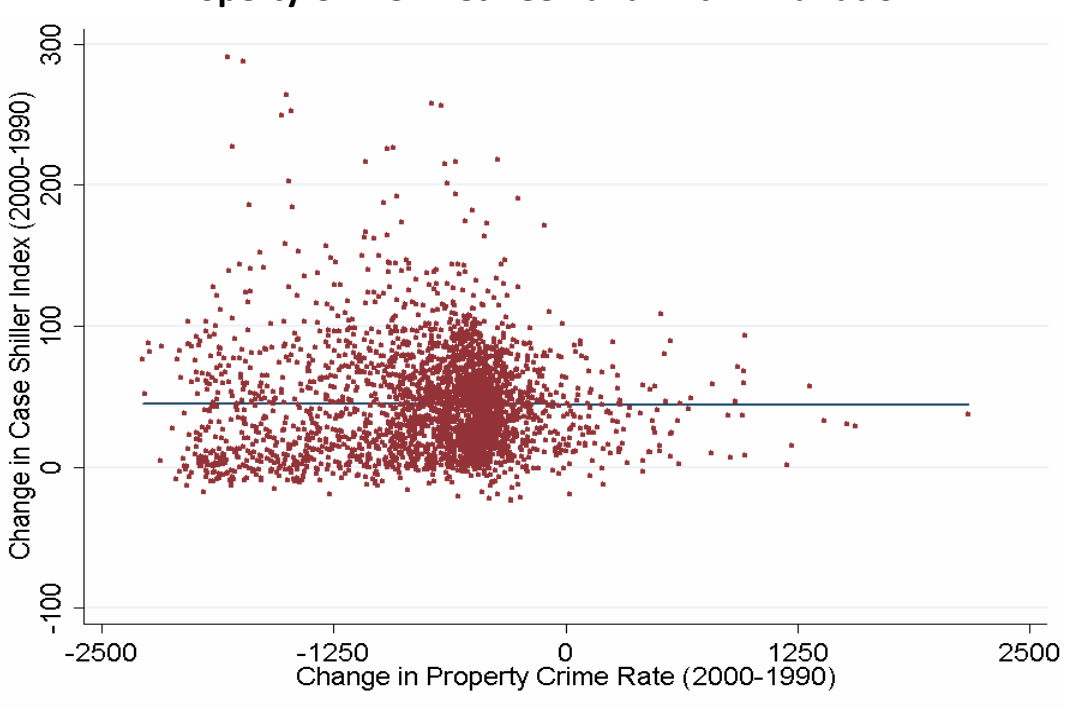

D. Property Crime - Within Variation Only

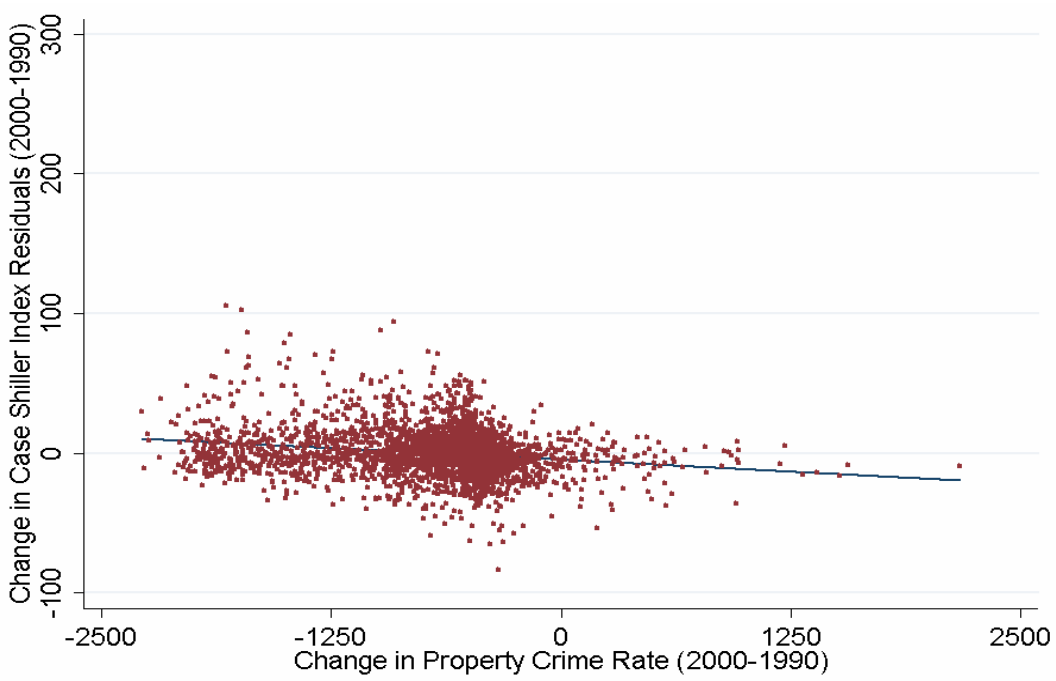

Notes: This figure illustrates the relationship between changes in the Case Shiller Index between 2000 and 1990 and changes in violent (Panel A \& Panel C) and property (Panel B \& Panel D) crimes over the same period. Each dot is an observation at the zip code level. Panels $A$ and $B$ graph raw changes, while Panels $C$ and $D$ graph the residuals from a regression of changes in the Case Shiller Index between 2000 and 1990 on year*MSA dummies. 
Figure 3. Annual Case Shiller Index Residuals by Crime Reduction Quartile

A. Violent Crime Reduction Quartiles

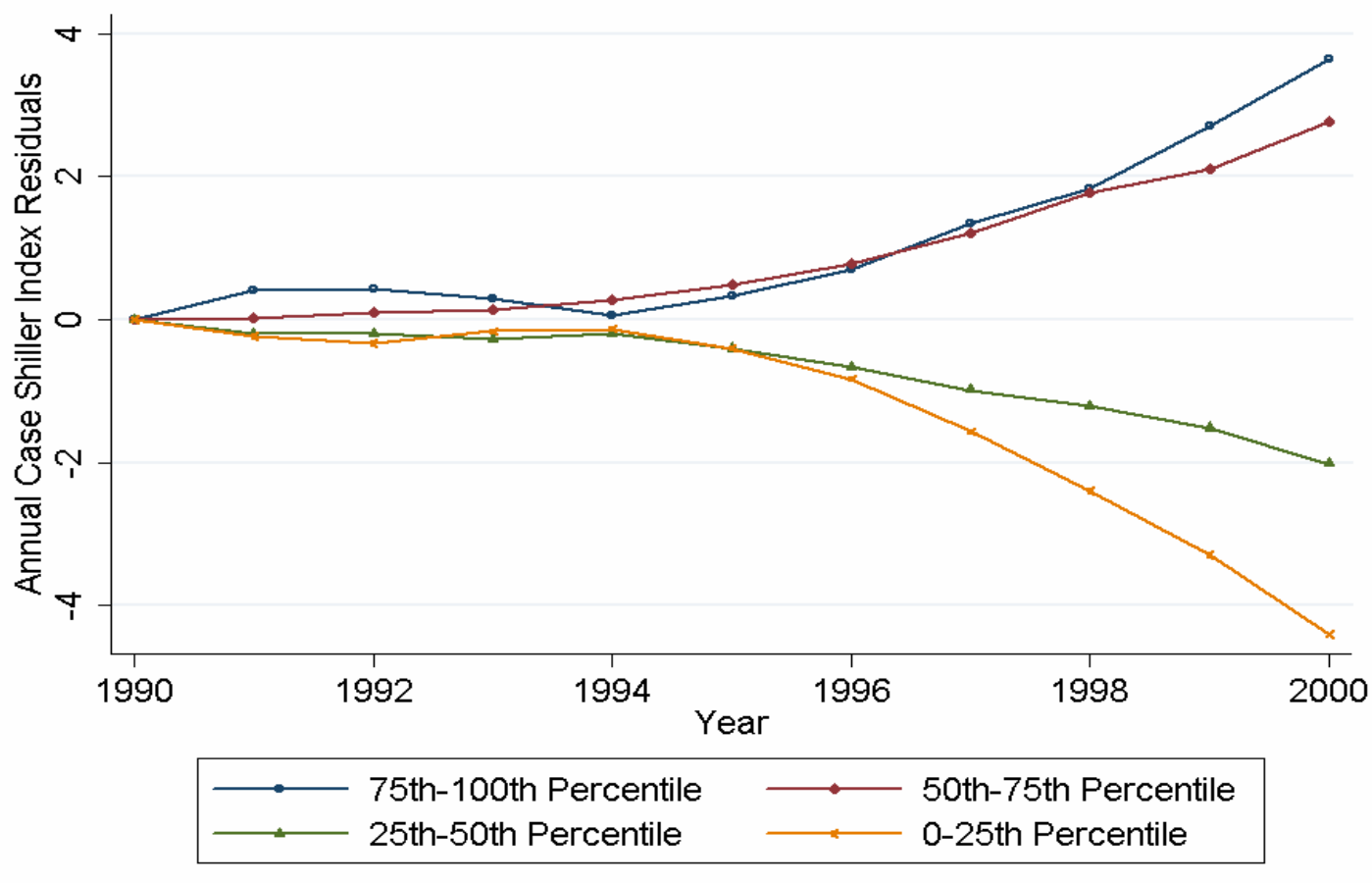

\section{B. Property Crime Reduction Quartiles}

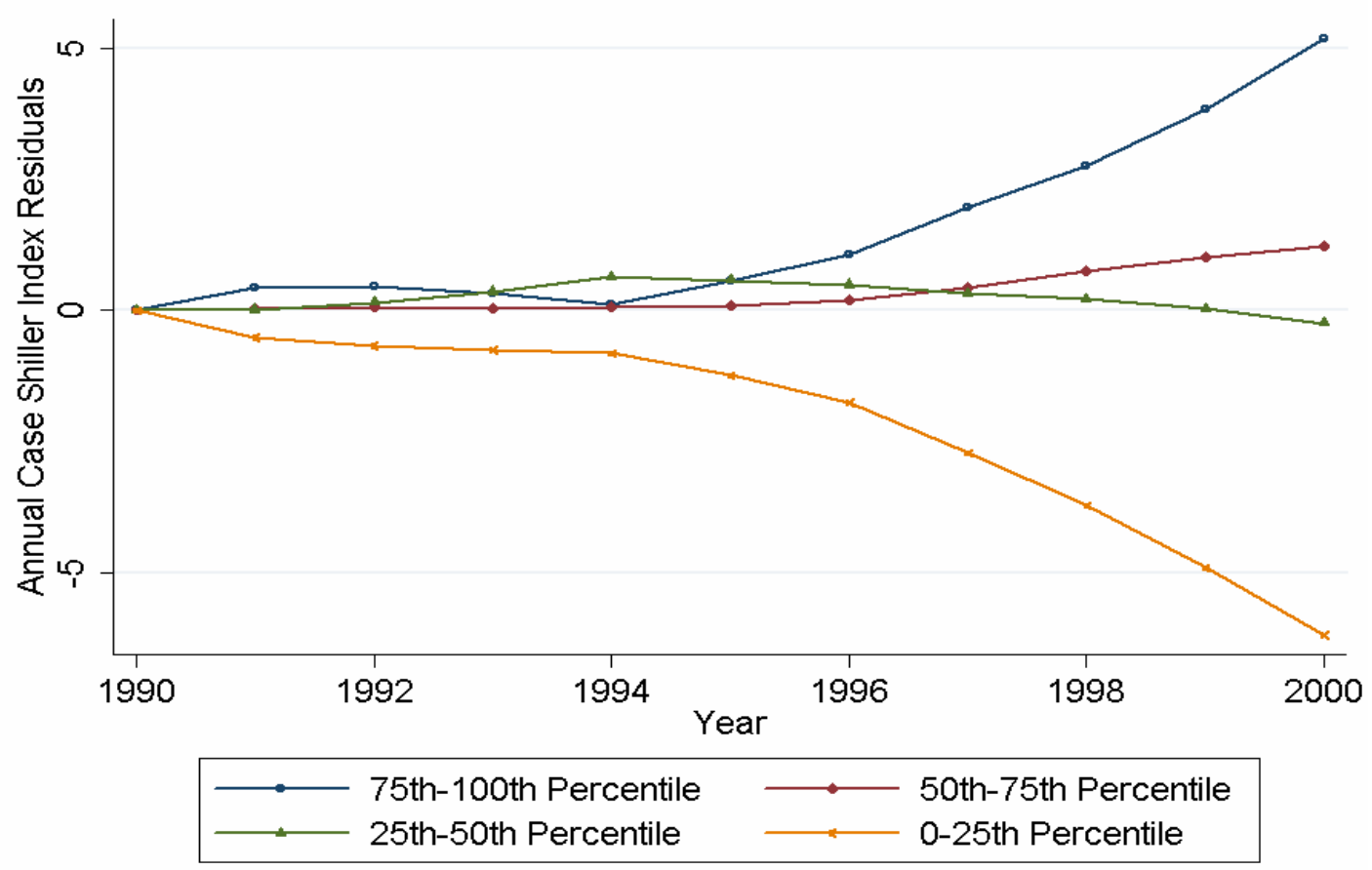

Notes: This figure plots year-to-year changes in residuals from a regression of the Case Shiller Index (2000 - 1990) on year*MSA dummies. The residuals are plotted separately for zip codes with different levels of violent (Panel A) and property (Panel B) crime reduction (2000 - 1990). For example, the line labeled "75th-100th Percentile" represents the $25 \%$ of zip codes experiencing the largest absolute crime reduction. 
Table 1. Summary Statistics

\begin{tabular}{|c|c|c|c|c|c|}
\hline & 1990 & $2000-1990$ & & 1990 & $2000-1990$ \\
\hline \multicolumn{6}{|c|}{ Control Variables Cont. } \\
\hline \multirow[t]{3}{*}{ Case Shiller Index } & 100 & 44.59 & Med. Household Income & 42110 & 14229 \\
\hline & $(0)$ & $(36.21)$ & & (14899) & $(12098)$ \\
\hline & [0] & {$[17.42]$} & & [12930] & [11569] \\
\hline \multirow[t]{3}{*}{ Violent Crime Rate } & 336 & -30.01 & $\%$ High School Grads & 80.35 & 3.31 \\
\hline & (219) & (83.85) & & $(11.65)$ & $(8.83)$ \\
\hline & [199] & [81.00] & & {$[10.79]$} & {$[8.45]$} \\
\hline \multirow[t]{3}{*}{ Property Crime Rate } & 3435 & -710.52 & $\%$ Age $0-17$ & 24.23 & 1.06 \\
\hline & $(1213)$ & $(513.07)$ & & $(5.59)$ & $(4.56)$ \\
\hline & [1047] & [475.53] & & [5.26] & [4.41] \\
\hline Control Variables & & & $\%$ Age $18-24$ & 9.75 & -1.47 \\
\hline \multirow{3}{*}{ \% Unemployed } & 5.68 & -0.60 & & $(4.08)$ & (3.53) \\
\hline & $(2.03)$ & $(2.93)$ & & [3.99] & [3.36] \\
\hline & [1.93] & [2.58] & $\%$ Age $25-44$ & 34.22 & -2.87 \\
\hline \multirow[t]{3}{*}{$\%$ Black } & 7.18 & 1.18 & & $(5.42)$ & $(4.73)$ \\
\hline & $(13.83)$ & $(7.48)$ & & [5.02] & [4.59] \\
\hline & [12.88] & [7.27] & $\%$ Age $45-64$ & 19.47 & 3.16 \\
\hline \multirow[t]{3}{*}{$\%$ Homeowner } & 67.68 & 0.75 & & (4.31) & $(4.23)$ \\
\hline & $(16.98)$ & $(10.43)$ & & [4.12] & [4.07] \\
\hline & [15.89] & [10.34] & Empowerment Zone & 0 & .007 \\
\hline \multirow[t]{3}{*}{ Pop per Square Mile } & 3221 & 345 & & (0) & $(.082)$ \\
\hline & $(3857)$ & $(1810)$ & & [0] & {$[.079]$} \\
\hline & [3583] & [1788] & Renewel Community & 0 & .011 \\
\hline \multirow[t]{3}{*}{$\%$ Foreign Nationals } & 4.63 & 2.08 & & (0) & $(.104)$ \\
\hline & (3.57) & (3.15) & & [0] & {$[.096]$} \\
\hline & [2.73] & {$[2.74]$} & Low Income Units/pop & 0.048 & -0.011 \\
\hline \multirow[t]{5}{*}{$\%$ Non-Citizens } & 6.41 & 2.04 & & $(1.63)$ & $(1.12)$ \\
\hline & $(7.93)$ & $(5.48)$ & & [1.61] & [1.12] \\
\hline & {$[6.28]$} & {$[5.24]$} & & & \\
\hline & & & No. of MSAs & 51 & 51 \\
\hline & & & No. of Zip Codes & 2922 & 2922 \\
\hline
\end{tabular}

Notes: Summary statistics are provided for all of the variables used in the analysis. Observations are at the zip code level. Conventional standard errors are presented in parentheses and within-MSA standard deviations are presented in brackets. The majority of the control variables are taken from the 1990 and 2000 census (using Geolytics to allow for consistent zip-code matching). Empowerment zones, renewel community zones, and low income units per population were obtained directly from public use data provided by the Department of Housing and Urban Development. 
Table 2. Changes in Crime and Property Values (2000-1990) - OLS Levels and Percentages

\begin{tabular}{|c|c|c|c|c|c|c|}
\hline \multirow{2}{*}{ Panel A } & \multicolumn{6}{|c|}{ Dep. Var: 2000-1990 Case Shiller Index Difference (1990 Level == 100 for each zip) } \\
\hline & $(1)$ & $(2)$ & $(3)$ & $(4)$ & $(5)$ & $(6)$ \\
\hline 2000-1990 Violent Crime Diff & $\begin{array}{l}-0.008 \\
(.009)\end{array}$ & $\begin{array}{c}-0.034 \\
(.005)^{* * *}\end{array}$ & $\begin{array}{c}-0.043 \\
(.005)^{* * *}\end{array}$ & & & \\
\hline 2000-1990 Property Crime Diff & & & & $\begin{array}{l}0.000 \\
(.001)\end{array}$ & $\begin{array}{c}-0.008 \\
(.001)^{* * *}\end{array}$ & $\begin{array}{c}-0.011 \\
(.001)^{* * *}\end{array}$ \\
\hline MSA Fixed Effects & & $\mathrm{x}$ & $\mathrm{x}$ & & $\mathrm{x}$ & $\mathrm{X}$ \\
\hline 2000-1990 Controls & & & $\mathrm{x}$ & & & $x$ \\
\hline R-Squared & 0.001 & 0.775 & 0.785 & 0.000 & 0.779 & 0.792 \\
\hline Observations & 2922 & 2922 & 2912 & 2922 & 2922 & 2912 \\
\hline \multicolumn{7}{|l|}{ Panel B } \\
\hline & $(1)$ & $(2)$ & $(3)$ & $(4)$ & $(5)$ & $(6)$ \\
\hline 2000-1990 Violent Crime \% Diff & $\begin{array}{c}-7.85 \\
(2.19)^{* * *}\end{array}$ & $\begin{array}{c}-10.94 \\
(1.42)^{* * *}\end{array}$ & $\begin{array}{c}-14.99 \\
(1.77)^{* * *}\end{array}$ & & & \\
\hline 2000-1990 Property Crime \% Diff & & & & $\begin{array}{l}-8.00 \\
(5.47)\end{array}$ & $\begin{array}{c}-32.59 \\
(3.45)^{* * *}\end{array}$ & $\begin{array}{c}-38.91 \\
(3.76)^{* * *}\end{array}$ \\
\hline MSA Fixed Effects & & $x$ & $x$ & & $x$ & $x$ \\
\hline 2000-1990 Controls & & & $x$ & & & $x$ \\
\hline R-Squared & 0.003 & 0.774 & 0.785 & 0.001 & 0.776 & 0.787 \\
\hline Observations & 2922 & 2922 & 2912 & 2922 & 2922 & 2912 \\
\hline
\end{tabular}

Notes: Regression coefficients and robust standard errrors are presented of the relationship between the change in the Case Shiller Index between 2000 and 1990 and changes in absolute violent and property crime (Panel A) and percent changes in violent and property crime (Panel B).

Observations are at the zip-code level. Columns (2), (3), (5), and (6) include MSA fixed effects for all 51 MSAs represented in the data sample.

Columns (3) and (6) include all of the 2000-1990 control variables presented in Table 1.

$* * *$ significant at $1 \%$ 


\section{Table 3. Correlation Between Crime Changes in Similar Zip Codes - First Stage Levels and Percentages}

\section{Dep. Var: 2000-1990 Crime Differences (as indicated)}

\section{Panel A}

2000-1990 Violent Crime Diff

2000-1990 Property Crime Diff

MSA Fixed Effects

2000-1990 Controls

R-Squared

Panel B

2000-1990 Violent Crime \% Diff

2000-1990 Property Crime \% Diff

MSA Fixed Effects

2000-1990 Controls

R-Squared

Observations
Observations

\begin{tabular}{ccc}
$(1)$ & $(2)$ & $(3)$ \\
\hline 0.855 & 0.900 & 0.850 \\
$(.020)^{* * *}$ & $(.023)^{* * *}$ & $(.026)^{* * *}$
\end{tabular}

Violent Crime Difference

Property Crime Difference

(4)

(5)

(6)

$\begin{array}{ccc}1.060 & 1.118 & 1.059 \\ (.010)^{* * *} & (.014)^{* * *} & (.016)^{* * *} \\ & \mathrm{X} & \mathrm{X} \\ & & \mathrm{X} \\ 0.749 & 0.789 & 0.803 \\ 2922 & 2922 & 2912\end{array}$

Property Crime Percent Difference

Violent Crime Percent Difference

\begin{tabular}{cccccc}
$(1)$ & $(2)$ & $(3)$ & $(4)$ & $(5)$ & $(6)$ \\
\hline 0.845 & 0.893 & 0.786 & 0.847 & 0.853 & 0.77 \\
$(.033)^{* * *}$ & $(.040)^{* * *}$ & $(.042)^{* * *}$ & $(.036)^{* * *}$ & $(.038)^{* * *}$ & $(.035)^{* * *}$
\end{tabular}

Notes: Each zip code in our data was matched with another zip code in a different area with the most similar 1990 violent and property crime levels. This table presents regression coefficients and robust standard errrors of the relationship between the change in crime between 2000 and 1990 and the change in crime of the matched zip code. Absolute violent and property crimes and percent changes in violent and property crimes are presented in Panel A and Panel B, respectively. Observations are at the zip-code level. Columns (2), (3), (5), and (6) include MSA fixed effects for all 51 MSAs represented in the data sample. Columns (3) and (6) include all of the 2000-1990 control variables presented in Table 1.

$* * *$ significant at $1 \%$ 
Table 4. Changes in Crime and Property Values (2000-1990) - IV Levels and Percentages

\begin{tabular}{|c|c|c|c|c|c|c|}
\hline \multirow{2}{*}{ Panel A } & \multicolumn{6}{|c|}{ Dep. Var: 2000-1990 Case Shiller Index Difference (1990 Level == 100 for each zip) } \\
\hline & $(1)$ & $(2)$ & (3) & (4) & (5) & (6) \\
\hline \multirow[t]{2}{*}{ 2000-1990 Violent Crime Diff (Instr.) } & 0.014 & -0.042 & -0.055 & & & \\
\hline & $(.013)$ & $(.006)^{* * *}$ & $(.008) * * *$ & & & \\
\hline \multirow[t]{2}{*}{ 2000-1990 Property Crime Diff (Instr.) } & & & & 0.002 & -0.008 & -0.010 \\
\hline & & & & $(.002)$ & $(.001)^{* * *}$ & $(.001)^{* * *}$ \\
\hline MSA Fixed Effects & & $x$ & $x$ & & $x$ & $x$ \\
\hline 2000-1990 Controls & & & $x$ & & & $X$ \\
\hline Observations & 2922 & 2922 & 2912 & 2922 & 2922 & 2912 \\
\hline \multicolumn{7}{|l|}{ Panel B } \\
\hline & $(1)$ & $(2)$ & (3) & (4) & (5) & (6) \\
\hline \multirow[t]{2}{*}{ 2000-1990 Violent Crime \% Diff (Instr.) } & -0.73 & -17.09 & -25.70 & & & \\
\hline & $(5.57)$ & $(2.88) * * *$ & $(4.14)^{* * *}$ & & & \\
\hline \multirow[t]{2}{*}{ 2000-1990 Property Crime \% Diff (Instr.) } & & & & 40.94 & -37.87 & -35.87 \\
\hline & & & & $(17.43)^{* *}$ & $(8.38)^{* * *}$ & $(9.31)^{* * *}$ \\
\hline MSA Fixed Effects & & $x$ & $x$ & & $x$ & $x$ \\
\hline 2000-1990 Controls & & & $x$ & & & $x$ \\
\hline Observations & 2922 & 2922 & 2912 & 2922 & 2922 & 2912 \\
\hline
\end{tabular}

Notes: Regression coefficients and robust standard errrors are presented of the relationship between the change in the Case Shiller Index between 2000 and 1990 and changes in absolute violent and property crime (Panel A) and percent changes in violent and property crime (Panel B). Observations are at the zip-code level. Changes in violent and property crime are instrumented with changes in violent and property crime of the out-of-MSAmatched zip codes based on 1990 crime levels. Columns (2), (3), (5), and (6) include MSA fixed effects for all 51 MSAs represented in the data sample. Columns (3) and (6) include all of the 2000-1990 control variables presented in Table 1.

** significant at $5 \% ; * *$ significant at $1 \%$ 
Appendix Table 1. Changes in Crime and Property Values (2000-1990) - OLS Levels and Percentages

Dep. Var: 2000-1990 Case Shiller Index Difference (1990 Level == 100 for each zip)

Panel A

2000-1990 Violent Crime Diff

2000-1990 Property Crime Diff

\begin{tabular}{ccc}
$(1)$ & $(2)$ & $(3)$ \\
\hline-0.019 & 0.003 & -0.002 \\
$(.015)$ & $(.008)$ & $(.008)$ \\
0.002 & -0.008 & -0.011 \\
$(.002)$ & $(.001)^{* * *}$ & $(.001)^{* * *}$ \\
& $X$ & $X$ \\
0.001 & & $X$ \\
2922 & 0.779 & 0.792 \\
& 2922 & 2912 \\
\hline
\end{tabular}

MSA Fixed Effects

2000-1990 Controls

R-Squared

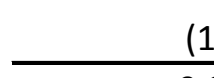

2000-1990 Violent Crime \% Diff

Panel B

2000-1990 Property Crime \% Diff

-9.95
$(3.00)^{* * *}$

(2) (3)

7.47

(7.56)

$(1.77)^{* *}$

$-7.96$

MSA Fixed Effects

2000-1990 Controls

R-Squared

0.003

2922

$-26.94$

$(2.04)^{* * *}$

Observations

$(4.39)^{* * *}$

$-26.98$

$(4.77)^{* * *}$

$X$

$\mathrm{x}$

$x$

0.777

0.788

2922

2912

Notes: Regression coefficients and robust standard errrors are presented of the relationship between the change in the Case Shiller Index between 2000 and 1990 and changes in absolute violent and property crime (Panel A) and percent changes in violent and property crime (Panel B). Observations are at the zip-code level. Columns (2), (3), (5), and (6) include MSA fixed effects for all 51 MSAs represented in the data sample.

Columns (3) and (6) include all of the 2000-1990 control variables presented in Table 1.

$* *$ significant at $5 \% ;{ }^{* *}$ significant at $1 \%$ 
Panel A

Dep. Var: 2000-1990 Case Shiller Index Difference (1990 Level == 100 for each zip)

\begin{tabular}{|c|c|c|c|c|c|c|}
\hline & (1) & (2) & (3) & (4) & $(5)$ & (6) \\
\hline 2000-1990 Violent Crime Diff & $\begin{array}{l}0.000 \\
(.008)\end{array}$ & $\begin{array}{c}-0.047 \\
(.005)^{* * *}\end{array}$ & $\begin{array}{c}-0.046 \\
(.005)^{* * *}\end{array}$ & & & \\
\hline 2000-1990 Property Crime Diff & & & & $\begin{array}{l}0.001 \\
(.001)\end{array}$ & $\begin{array}{c}-0.011 \\
(.001)^{* * *}\end{array}$ & $\begin{array}{c}-0.011 \\
(.001)^{* * *}\end{array}$ \\
\hline 1990 Med. Housing Value $(\$ 1,000 s)$ & $\begin{array}{c}-0.063 \\
(.008)^{* * *}\end{array}$ & $\begin{array}{c}0.066 \\
(.005)^{* * *}\end{array}$ & $\begin{array}{c}0.062 \\
(.006)^{* * *}\end{array}$ & $\begin{array}{c}-0.064 \\
(.008)^{* * *}\end{array}$ & $\begin{array}{c}0.073 \\
(.005)^{* * *}\end{array}$ & $\begin{array}{c}0.065 \\
(.006)^{* * *}\end{array}$ \\
\hline $\begin{array}{l}\text { MSA Fixed Effects } \\
2000-1990 \text { Controls }\end{array}$ & & $\mathrm{x}$ & $\begin{array}{l}x \\
x\end{array}$ & & $\mathrm{x}$ & $\begin{array}{l}x \\
x\end{array}$ \\
\hline R-Squared & 0.025 & 0.789 & 0.795 & 0.025 & 0.797 & 0.802 \\
\hline Observations & 2922 & 2922 & 2912 & 2922 & 2922 & 2912 \\
\hline \multicolumn{6}{|l|}{ Panel B } & (6) \\
\hline 2000-1990 Violent Crime \% Diff & $\begin{array}{c}-6.39 \\
(2.11)^{* * *}\end{array}$ & $\begin{array}{c}-13.64 \\
(1.66)^{* * *}\end{array}$ & $\begin{array}{c}-14.56 \\
(1.75)^{* * *}\end{array}$ & & & \\
\hline 2000-1990 Property Crime \% Diff & & & & $\begin{array}{l}-8.22 \\
(5.35)\end{array}$ & $\begin{array}{c}-37.20 \\
(3.68)^{* * *}\end{array}$ & $\begin{array}{c}-37.95 \\
(3.72) * * *\end{array}$ \\
\hline 1990 Med. Housing Value $(\$ 1,000 s)$ & $\begin{array}{c}-0.062 \\
(.008)^{* * *}\end{array}$ & $\begin{array}{c}0.060 \\
(.005)^{* * *}\end{array}$ & $\begin{array}{c}0.058 \\
(.006)^{* * *}\end{array}$ & $\begin{array}{c}-0.063 \\
(.008) * * *\end{array}$ & $\begin{array}{c}0.059 \\
(.005)^{* * *}\end{array}$ & $\begin{array}{c}0.058 \\
(.006)^{* * *}\end{array}$ \\
\hline MSA Fixed Effects & & $x$ & $x$ & & $x$ & $x$ \\
\hline 2000-1990 Controls & & & $x$ & & & $x$ \\
\hline R-Squared & 0.027 & 0.786 & 0.794 & 0.026 & 0.788 & 0.795 \\
\hline Observations & 2922 & 2922 & 2912 & 2922 & 2922 & 2912 \\
\hline
\end{tabular}

Notes: Regression coefficients and robust standard errrors are presented of the relationship between the change in the Case Shiller Index between 2000 and 1990 and changes in absolute violent and property crime (Panel A) and percent changes in violent and property crime (Panel B). Observations are at the zip-code level. Columns (2), (3), (5), and (6) include MSA fixed effects for all 51 MSAs represented in the data sample. Columns (3) and (6) include all of the 2000-1990 control variables presented in Table 1.

$* * *$ significant at $1 \%$ 